\title{
Research on Information and Feedback System in Experimental Teaching and Management in Colleges

\author{
Yongming Kang ${ }^{1, a}$, Naiji Ma ${ }^{1, b}$ and Haojian Zhou ${ }^{1, c}$ \\ ${ }^{1}$ College of Automobile \& Architectural Engineering, Beihua University, China

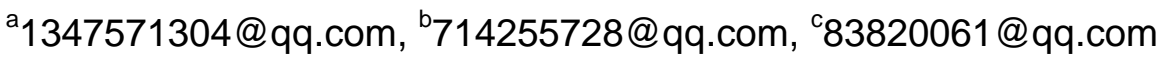

Keywords: Experimental teaching; Management; Information; Information feedback system

\begin{abstract}
Through the analysis of the information source, the information quantity and the information transmission way in the experimental teaching and management system of colleges and universities, it is necessary to establish the information and information feedback system to obtain the quality information of the teaching object. For the actual experimental teaching and management system Information and information feedback system in-depth analysis, to better serve the experimental teaching, improve the quality of teaching in colleges and universities.
\end{abstract}

\section{Introduction}

Experimental teaching and management of information systems is a subsystem in the education information system, the control of the subsystems of the effect of good and bad will directly affect the effectiveness of education. The form and means of modern educational information transmission are varied, not in books and class as a single limit.

In the current experimental teaching and management reform, advanced laboratory equipment, instruments, instrumentation, components and materials, advanced experiment teaching methods, management experience and experiment means constantly emerging, the advanced experience of foreign constantly introduced, and development level of students in the experimental teaching of control, and many other information constitute the complex information system. It can be seen that the establishment of a better experimental teaching and management of information, information feedback system is very necessary, it is also a new field of the current educational science research , the purpose is to use the basic principles of information theory to solve the experimental teaching and management system information transmission, processing, storage, control and other practical problems[1-3].

\section{Determining the Source of Information in the Experimental Teaching and Management System}

The information sources in the experiment teaching and management system can be roughly divided into two categories: one is the teaching information source of experiment. This kind of information source is based on the premise of the curriculum, to determine the source of information that is to determine the course, so it can be referred to as the first type of information source. The second category is the information source of experimental teaching management.

This kind of information source is derived from the first type of information source at the same time, it is the management information source of people, money and object for the unit, referred to as the second type of information source[4-6]. These two types of information sources constitute the total information source in the experimental teaching and management system. It is to achieve a certain educational purposes, to achieve a certain goal of training to pass out the collection of information, in the form of disciplines, courses, and the activities of human participation in the system.In the experimental teaching and management system, to determine the course of this information source is to determine the amount of information; to determine the people, fund ,material and other information sources to determine the ability to pass information. 


\section{Determining the Amount of Information in the Experimental Teaching and Management System}

The information sources in the experiment teaching and management system can be roughly divided into two categories: one is the teaching information source of experiment. This kind of information source is based on the premise of the curriculum, to determine the source of information that is to determine the course, so it can be referred to as the first type of information source. The second category is the information source of experimental teaching management.

College training goal, for the moment, can be divided into two categories: basic training goal and professional training goal. The amount of information that can be conveyed is determined by the target of training, that is, depending on the direction of basic education and professional education. By determining the amount of information sources in the second category, the capacity of the experimental teaching and management system can be assessed. The second category of information source is mainly people, fund, and material. People refer to teachers (lab instructors) and the taught people (students), that is, the teaching level of the educators' marks the ability to impart information; the amount of learning that the taught can afford is the ability to receive information. Material refers to the necessary laboratory equipment, instruments, instrumentation, components, materials, data and existing information transmission means (electrochemical, computer systems, listening equipment) and so on. Fund means the funds necessary to complete the transmission of information and the necessary funds to develop the transmission of information systems. These three factors constitute the ability of information transmission in the experimental teaching and management system.

\section{Determine the Information Imparting Pathway.}

The information imparting pathway is the information link between the information source and the information receiver, also known as the information transmission channel. Determine an information imparting pathway to determine the function of this information system. The control of experimental teaching and management system is realized by the information transmission in the system.

Fig. 1 summarizes the ways and relationships of information transmission in experimental teaching and management systems in colleges and universities. The first category of information source is composed of advanced technology report and information, experimental textbook and theoretical textbook. Information from the first type of information source output through the second type of information sources (equipment and materials, lab instructor, scientific research, theoretical teachers) synthesis, essence, refined to become controlled information. The controlled information passes through the department's main channel - laboratory to impart the object. The dotted line in the figure represents the information transmission path within the source, and the solid line part represents the primary information transfer path from the information source[7-10]. The figure expresses the inevitable connection between the information in the experimental teaching and management system and teaching management of theory, thus constituting the mainstream of educational information. It can be seen that the experimental teaching and management system are the component of the whole educational system. From the control point of view, it actually constitutes a system of open-loop state. The information that the lab receives from the information source is disturbed, the kind of disturbance is more and more complex. For example, the goal criterion is unrealistic, in the condition of no information feedback decision-making errors, textbook selection and other factors. The information output by the lab is also subject to a second disturbance to impart to the imparting object. In the second disturbance, the main interference are: the coordination of theoretical and experimental teaching, social factors, experimental funds, equipment materials, the quality of laboratory technicians, the ability to impart information, etc. The system in open-loop state is not adapted to the subject of the transfer of quality information. We need an 
information system that can control and know how the information is outgoing, which is the information and letter feedback system, the closed-loop system.

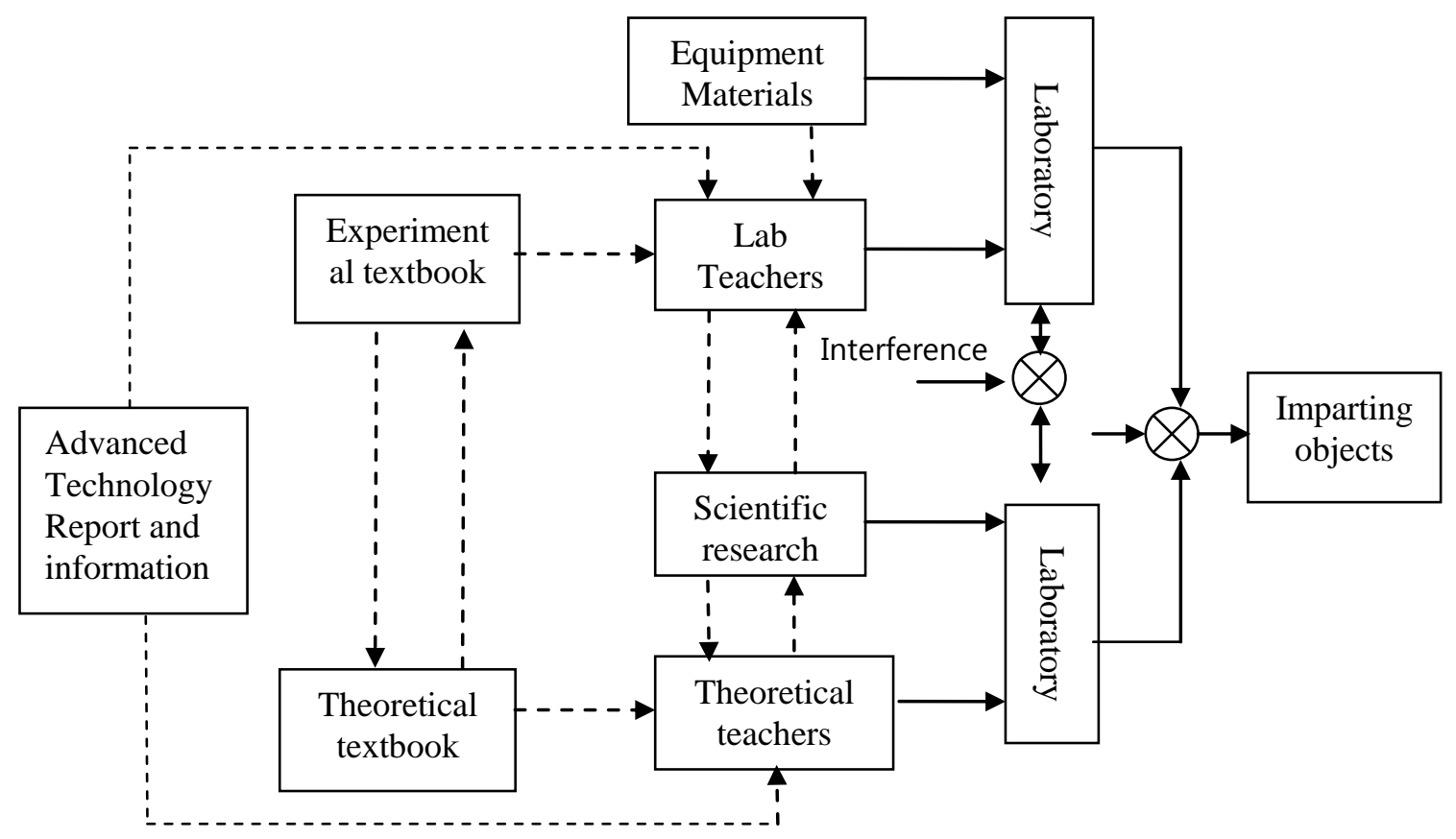

Figure 1. Information imparting pathway

\section{Information and Feedback in Experimental Teaching and Management System}

Feedback is the basic method and condition of control system. The so-called feedback is to remove the information output from the control of the information, and then return the information input end of the system, which is the basis of evaluating the system state and adjusting the next control, which is called the feedback process. The purpose of feedback is to enable the Controller to know its control results and to regulate the process of next control by comparing it with the target standard.

In Fig. 2, we put the actual experimental teaching and management system using the concept of information control theory with information control chart described, that is, information and information feedback system. In this system there are many small links constitute, each link is composed of its own feedback. Such as target standards, decision-making bodies, controlled information (a collection of information in the laboratory) in this part of the interference, then through this level of feedback back to the target standard, by the decision-making body to determine which kind of interference, and then use a certain method to exclude interference, to ensure that the quality of the information after the control meet the standards, with the delivery of information level and ability.

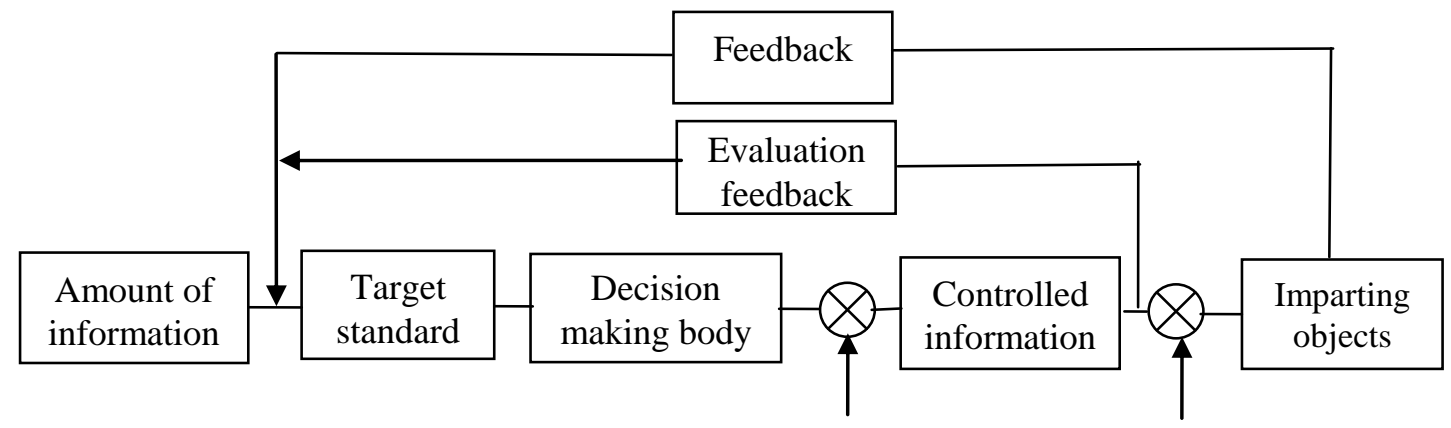

Figure 2. Information feedback system 
Feedback information should also have two basic conditions: one is accuracy and the second is rapid timeliness. Accuracy refers to the feedback information must be true and reliable; the wrong information can lead to wrong decision making system control ineffective. Rapid timeliness means that the speed of feedback is greater than the speed of the information state change in the controlled system, that is, the feedback is done before the next control decision, and otherwise the next control can not be adjusted. Visible, both are indispensable.

In the actual experimental teaching and management system, the transmission of these feedback information requires a strong professional organization to complete, and converts these feedback information into observable variables and controllable variables, so that the controller can distinguish between the truth and false, exclude interference, and understand the real situation of the control object to make decisions.

\section{Summary}

In short, information and information feedback system plays an important role in experimental teaching and management. It is necessary for us to carry out in-depth discussion and research in this area so as to better serve the experimental teaching and improve the teaching quality.

\section{References}

[1] G.J. Shi: Science and Technology, Vol. 25 (2004) No.5,p.41. (In Chinese)

[2] F.R. Liu: Heilongjiang Education, Vol. 31 (2010) No.4,p.17. (In Chinese)

[3] K.G. Bi: Journal of Northeast University of Finance and Economics, Vol. 80 (2012) No.2,p.87. (In Chinese)

[4] Y. Wang and X.F. Wang: Fundamentals of Modern Cybernetics (Higher Education Press, China 1995).

[5] Q.R. Sui and X.Y Liu: Information Service, Vol. 248 (2017) No.2,p.59. (In Chinese)

[6] J.K. Ge, C.M.Wan and Y.J Pei: Software Engineers, Vol. 142 (2014) No.1,p.39.

[7] Q.R. Sui,X.Y Liu and Z.X Han: Journal of Economic Management Cadre College of Jilin Province, Vol. 161 (2016) No.2,p.134. (In Chinese)

[8] Z.G. Zhang: Journal of Jilin Institute of Chemical Engineering, Vol. 28 (2011) No.12,p.79. (In Chinese)

[9] A. G. Zhang: Teaching quality assurance and monitoring system theory and practice (Beijing Jiaotong University Press, China 2004).

[10] X.F. He, S.J.Cao and X.R Dong: Educational and teaching Forum, Vol. 52 (2013) No.12,p.36. (In Chinese) 